\title{
Subcutaneous Endoscopy in Plastic and Reconstructive Surgery
}

\author{
Bharatendu Swain ${ }^{1}$ \\ ${ }^{1}$ Department of Plastic Surgery, Aakar Asha Hospital, Hyderabad, \\ India
}

Indian J Plast Surg 2021;54:297-301.

\begin{abstract}
Address for correspondence Bharatendu Swain, MS, MCh, Department of Plastic Surgery, Aakar Asha Hospital, 4-S, Royal Heritage Apts., Srinagar Colony, Hyderabad 500073, India (e-mail: bharatendu.swain@gmail.com).
\end{abstract}

\begin{abstract}
Keywords

- endoscopy

- minimal access

- plastic and reconstructive surgery

Background Scar visibility is a major deterrent to patients seeking reconstructive surgery. Endoscopic surgery can address a wide range of problems, from minimizing or concealing scars to improving access and outcomes in certain situations. This case series includes a wide range of reconstructive surgery problems addressed by subcutaneous endoscopic surgery. Having one or more trained assistants is a major deterrent to the performance of endoscopic surgery by the lone practitioner. The single (or two-port technique for muscle harvest) used in most cases simplifies subcutaneous endoscopic surgery.

Methods A single-port endoscopy technique, with a 4-mm, 30-degree side viewing telescope and sheath, optical camera and cold light source, was used. Case records were reviewed for access incisions, procedure abandonment, postoperative pain, complications, and patient satisfaction.

Results A total of 53 endoscopic surgical episodes between 2003 and 2013 were reviewed. Using a single port, most cases were done successfully. The access site was changed peroperatively in one case. Complications included transient nerve palsy in one case, which recovered completely. There was minimal intraoperative bleeding. Postoperative pain was low except in one case and managed with minimal analgesia. Patient satisfaction was high in all cases.

Conclusions Subsurface endoscopy done on a wide range of reconstructive surgery procedures and resulted in minimal scars and high patient satisfaction.
\end{abstract}

\section{Introduction}

Early enthusiasm for endoscopy in reconstructive surgery in the mid-1980s gave way to its major applications in aesthetic surgery after a decade, perhaps in keeping with the growing predominance of aesthetic surgery practice. This study examines past experiences with subsurface endoscopy in reconstructive surgery, evolution of technique, and its application for newer indications. The author has applied subsurface endoscopy to several known and some hitherto unknown situations in his practice, over a decade, with pleasing results. Despite a steep learning curve for the intricacies of subsurface maneuvers of tunnelling, dissection, hemostasis amidst the smoke and smudging of the telescope tip, and the difficulty of dissection at a distance from the hands, with stereoscopic vision, the encouraging results make it a worthwhile technique. published online September 16, 2021
DOI https://doi.org/ $10.1055 / \mathrm{s}-0041-1734580$ ISSN 0970-0358
(C) 2021. Association of Plastic Surgeons of India.

This is an open access article published by Thieme under the terms of the Creative Commons Attribution-NonDerivative-NonCommercial-License, permitting copying and reproduction so long as the original work is given appropriate credit. Contents may not be used for commercial purposes, or adapted, remixed, transformed or built upon. (https://creativecommons.org/licenses/by-nc-nd/4.0/). Thieme Medical and Scientific Publishers Pvt. Ltd. A-12, 2nd Floor, Sector 2, Noida-201301 UP, India 


\section{Methods}

This is a review of a case series of 52 patients who underwent 53 subcutaneous endoscopy procedures over a decade (2003 December-September 2013 and November 2019-February 2020) in various anatomic locations of the body and for diverse indications, ranging from removal of lumps to muscle harvest; there was no gender or age exclusion criteria in this study.

The endoscopy maneuvers either constituted the major part of the entire procedure or formed part of the surgical episode.

Details in the case records pertaining to patient particulars and preoperative clinical and laboratory/imaging evaluation were obtained. Preoperative consideration of endoscopy versus a conventional procedure had been discussed with the patient and guardian (s) in case of minors, and consent obtained. Operating time and observations on technical ease/difficulty during the procedures were noted. Visual analog scale (VAS) scores for pain within 24 hours following surgery were noted (levels of none [0]/mild [1-4]/moderate [5-8] and severe [9-10]). VAS scores for satisfaction following surgery were noted at last review (none [0]/low [1-4]/ moderate [5-8] and high [9-10]) The patients had been followed-up for a period ranging from 1 month to 12 years.

Access incisions were placed behind the frontotemporal hairline, intraoral region, conjunctiva, axilla, umbilicus, areola, or skin in the vicinity of the area of dissection. Access incision sizes ranged from $1.0 \mathrm{~cm}$ to $4.0 \mathrm{~cm}$ and were straight stab, zig-zag or hair follicle-preserving incisions. The plane of dissection was subcutaneous, subfascial, subperiosteal, or subgaleal. Most cases were operated through a single incision.

A 4-mm, 30-degree viewing endoscope, connected to cold light source and 3 chip-camera system (Karl Storz, Germany), was used along with suction/irrigation in all cases. Instrumentation included periosteal elevators, curved and straight, dissecting scissors, nerve hooks and angled graspers. Hemostasis was secured with bipolar or monopolar cautery. Apart from the telescope sheath with a terminal fenestrated guard, which was the primary soft-tissue retractor, commonly used retractors like Langenbeck or Czerny or, sometimes, the Killian retractor were used for additional retraction. Carbon dioxide insufflation or balloon dilatation was not used in any of the cases. In most cases, the author operated the endoscope with his left hand and performed maneuvers with the right hand; nonendoscopic assistance was for tissue retraction.

\section{Results}

A total of 53 procedures were performed on 52 patients from December 2003 to August 2013 and from August 2019 to February 2020 ( - Table 1). As many as 47 of the 53 procedures were done for reconstructive reasons, and only 6 were done for purely cosmetic reasons. The age of the patients ranged from 1 year to 60 years. A total of 24 patients were male and 28 were female. In none of the cases was the procedure abandoned for open surgery. In one case of a large epidermoid cyst of the left cheek, the access route was changed from intraoral to sideburn margin, subcutaneous route, due to a difficulty in access.

There was one complication related to the procedure in a case of excision of an external angular dermoid, where there was transient paralysis of the frontal branch of the facial nerve, which resolved over 3 months. The duration of the procedures ranged from 20 minutes to 190 minutes. The duration of surgery for a particular procedure and for the series, reduced progressively with experience. Pain scores were consistently below 4 except in one case. The satisfaction rates were high in all cases, including the patient who had transient nerve palsy.

For the face, 17 cases of upper third, 10 cases of middle third, and 6 cases of lower third procedures were done endoscopically. There were 6 cases of endoscopic procedures in the neck region, totaling 39 cases done in the head and neck region. Eight procedures involving the chest and six procedures of the abdomen and lower limbs were performed endoscopically. One patient underwent endoscopic placement of a dermis graft in the depressed area of her right cheek and had an endoscopy-aided intraoral insertion (vertical incisions) of a silicone chin implant. The procedures performed are summarized category-wise in - Table $\mathbf{1}$.

Two representative cases are presented below. One is a novel method of excising a deep-seated vascular malformation, and the other is part of a novel technique of flap cover. The common thread in both cases has been satisfying results with invisible or minimally visible scars.

\section{Case 1}

Excision of vascular malformation of cheek-A 27-year-old, unmarried lady presented with a bluish swelling of her right cheek ( - Fig. 1A). Based on the clinical signs of compressibility, blanching on pressure and surface color Doppler findings,
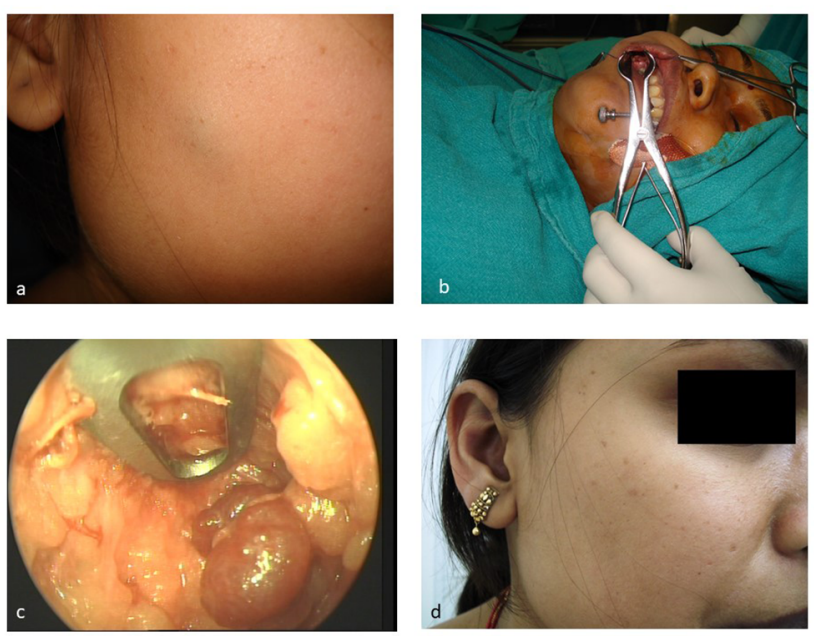

Fig. 1 (A) Preop vascular malformation right cheek. (B) Intraoral approach to vascular malformation. (C) Endoscopic view of vascular malformation. (D) Postop vascular malformation right cheek. 
Table 1 Summary of procedures

\begin{tabular}{|c|c|c|}
\hline $\begin{array}{l}\text { Category of } \\
\text { procedure }\end{array}$ & Summarized details of surgery (number of procedures) & Total number \\
\hline Aesthetic procedures & $\begin{array}{l}\text { Brow lift for brow ptosis (4) } \\
\text { Endo-assisted midface lift for midface sag (2) }\end{array}$ & 6 \\
\hline \multirow{9}{*}{$\begin{array}{l}\text { Subsurface lump } \\
\text { excisions of }\end{array}$} & External angular dermoid (5) & \multirow[t]{9}{*}{17} \\
\hline & Frontal osteoma ostectomy (3) & \\
\hline & Forehead lipoma (1) & \\
\hline & Forehead neurofibroma (1) & \\
\hline & Epidermoid cyst cheek (1) & \\
\hline & Lipoma lower jaw (1) & \\
\hline & Branchial sinus (2) & \\
\hline & Fibroadenoma and plication of breast tissue (2) & \\
\hline & Left chest multilobed intramuscular lipoma (1) & \\
\hline Fracture fixation & $\begin{array}{l}\text { Depressed fracture frontal bone (1) } \\
\text { Medial orbital wall fracture repositioning and placement of onlay nasal septal graft (2) }\end{array}$ & 03 \\
\hline \multirow{2}{*}{$\begin{array}{l}\text { Excision of vascular } \\
\text { lesions }\end{array}$} & Clipping and excision of aneurysm of left supraorbital artery (1) & \multirow[t]{2}{*}{02} \\
\hline & Intraoral excision of venous malformation right cheek (1) & \\
\hline \multirow[t]{5}{*}{ Tissue harvest } & Latissimus dorsi flap (2) & \multirow[t]{5}{*}{08} \\
\hline & 9th rib harvest (1) & \\
\hline & Rectus abdominis muscle (3) & \\
\hline & Sural nerve (1) & \\
\hline & Tailored fascia lata (1) & \\
\hline \multirow{4}{*}{$\begin{array}{l}\text { Expander and implant } \\
\text { placement }\end{array}$} & Tissue expander for Microtia (1) & \multirow[t]{4}{*}{05} \\
\hline & Tissue expander for depressed scar of left thigh (1) & \\
\hline & Chin implant for microgenia (2) & \\
\hline & Breast implant for hypoplasia of right breast (1) & \\
\hline \multirow[t]{7}{*}{ Miscellaneous } & Insertion of dermis-fat graft for Romberg disease (1) & \multirow[t]{7}{*}{12} \\
\hline & Insertion of dermis-fat graft for right preauricular-cheek depressed area (1) & \\
\hline & Endoscopy aided temporalis muscle transfer (1) & \\
\hline & $\begin{array}{l}\text { Endoscopic intraoral release of post traumatic entrapment neuropathy right infraorbital } \\
\text { nerve (1) }\end{array}$ & \\
\hline & $\begin{array}{l}\text { Endoscopy aided rib harvest and rectus muscle plication for congenital sternal dehiscence } \\
\text { (1) }\end{array}$ & \\
\hline & Transaxillary release of congenital torticollis (4) & \\
\hline & Intraoral endoscopic bilateral masseter reduction (3) & \\
\hline
\end{tabular}

a diagnosis of venous malformation of right cheek was made. As the patient was unwilling to accept an external scar, and experiencing difficulty in access through a subciliary incision, an intraoral procedure was considered. Through an intraoral endoscopic approach, with a Killian nasal forceps used to retract the soft tissues and facilitate excision (- Fig. 1B), the malformation was gently teased off the surrounding soft tissues and feeder vessels cauterized with bipolar cautery (-Fig. 1C). The tortuous mass of vessel malformation was excised completely. There was no external scar ( - Fig. 1D).

\section{Case 2}

Endoscopic harvest of upper rectus abdominis muscle-A 30-year-old man was involved in a road accident with loss of right ulnar forearm skin and subjacent muscles with segmental loss of the ulnar artery; the entire right thumb metacarpal along with extensor pollicis longus and extensor pollicis brevis tendons and the skin of the dorsum of thumb and first web were missing ( - Fig. 2A, B).

After counselling about the risks of doing a free-tissue transfer in a single artery forearm, he opted for a pedicled flap. A groin flap was considered but not done due to the bulk of tissue, which would have hindered movement across the first web and given an ugly appearance. The distal thumb was held to length in an external fixator and the raw areas covered, in a novel technique, with an endoscopically harvested, upper rectus abdominis pedicled flap delivered at the umbilicus, and skin grafted ( - Fig. 2C, D). After 1 month, the muscle flap was divided. 
Six weeks later, the flap was slit along the mid-dorsal axis of the right thumb; on splitting the muscle, brisk bleeding was encountered for which hemostasis was done with electrocautery. A 5.2-cm long, iliac bone graft was inserted in the bony gap with a dorsal strut straddling the dorsum of proximal phalanx for better bony contact; the bone graft was held in place with 4-hole plate and screws distally and two screws proximally. The external fixator was dismantled. The entire bone graft survived, presumably from the rich blood supply of the muscle ( - Fig. 3A).

One year later, an arthrolysis of the 1st carpometacarpal (CMC) joint was done with split abductor pollicis longus tendon gap arthroplasty. It resulted in 10 degrees of opposition. Seven years later, he underwent a silicone-carved block interposition arthroplasty with resultant 35 degree of opposition at the neo-CMC joint. He is now able to grip objects and write with a pen. The thumb appearance is sleek

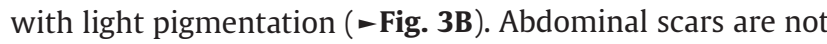
prominent ( - Fig. $3 \mathbf{3 C}$ ).
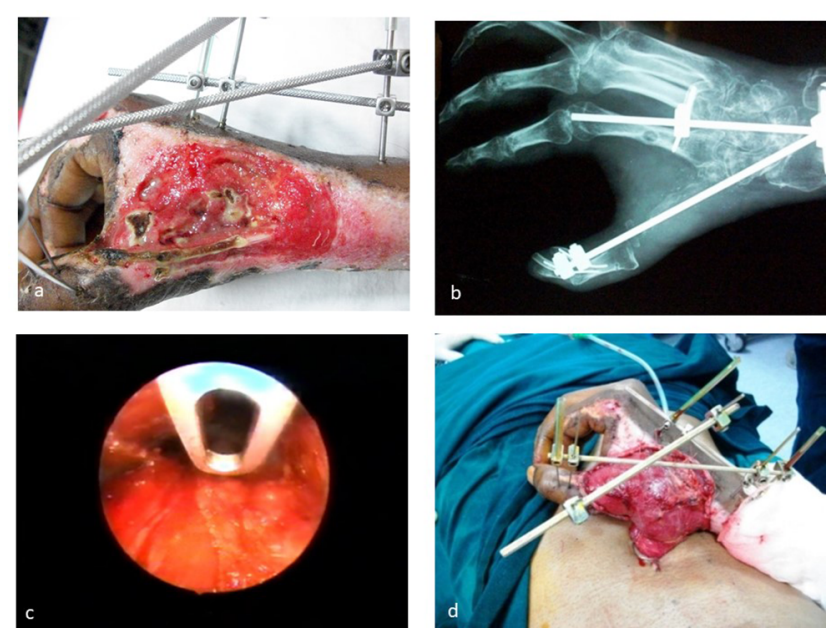

Fig. 2 (A) View of wound right hand and forearm after external fixation. (B) Preop X-ray showing bone loss of right 1st metacarpal. (C) Endoscopic view-rectus muscle exposed. (D) After coverage with pedicled rectus muscle flap.

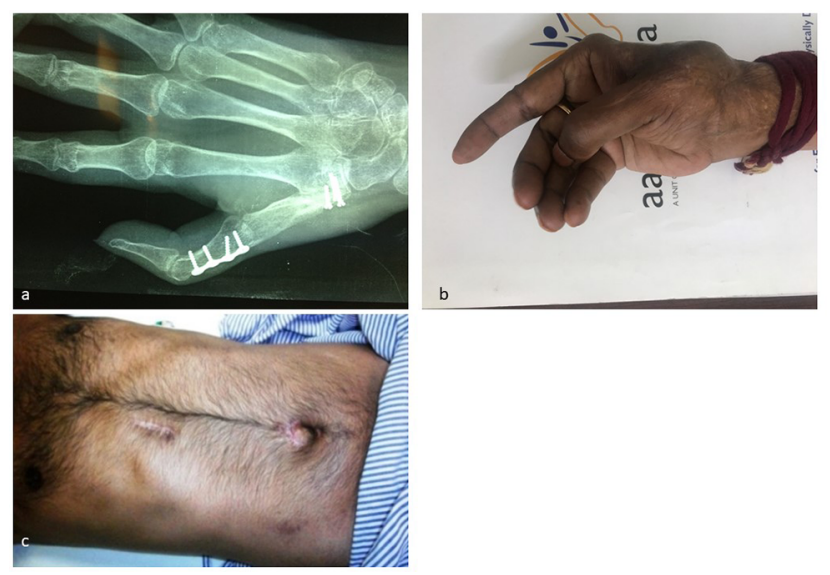

Fig. 3 (A) X-ray 9 months after bone grafting right thumb. (B) Right thumb movement after 7 years. (C) Inconspicuous upper abdominal scar after 2 years.

\section{Discussion}

Hippocrates, in $400 \mathrm{BC}$, examined hemorrhoids with a speculum. ${ }^{1}$ In modern times, cold light with fiberoptic technology in the 1950s paved the way for endoscopy. The miniature chip camera in 1982, which was connected to a television screen, introduced surgeons to stereoscopic surgery. ${ }^{1}$ It was Phillipe Mouret in 1987 who performed the first laparoscopic cholecystectomy and ushered the large-scale application of surgical endoscopy. ${ }^{1}$

Although Chow led the way in reconstructive surgery with the two-portal method for carpal tunnel release in $1984,{ }^{2}$ the use of minimally invasive surgery was adopted largely in cosmetic surgery. By 1990, the University of Alabama at Birmingham reported their clinical experience in endoscopy, including endoscopic browlift. ${ }^{3}$ Soon, endoscopic breast augmentation by the transaxillary and transumbilical routes, face lifts, and abdominoplasty were reported. ${ }^{4-7}$ Myriad applications in plastic surgery were soon reported; removal of benign lesions, ${ }^{8}$ decompressive fasciotomy for extremity compartment syndrome, ${ }^{9}$ or retrieval of spare body parts such as tendon, ${ }^{10}$ vein ${ }^{11}$ or nerve ${ }^{12}$ grafts. Congenital deformities such as torticollis ${ }^{13}$ or dermoid, especially in children have lent themselves to the endoscopic approach. ${ }^{14}$ Facial fractures may be directly or indirectly repaired. ${ }^{15}$ Other indications include the remote insertion of tissue expanders ${ }^{16}$ or harvest of local or free adipofascial $^{17}$ muscle ${ }^{18,19}$ and visceral flaps ${ }^{20} u$ sing endoscopy. Most endoscopic surgeons use a multiport technique which brings in additional small scars.

Instrumentation, especially for retaining subcutaneous spaces created by dissection, has been the biggest constraint in the development of subcutaneous endoscopic surgery. Unlike cavitary endoscopy with preformed working spaces, which can be easily distended by gas, subcutaneous endoscopy entails dissection of spaces and retention in all axes to facilitate dissection, especially when the base is not firm (as in the breast). Eaves et al designed a retractor mounted endoscope to facilitate dissection. ${ }^{21}$

In the present series of 53 (-Table $\mathbf{1}$ ) endoscopic procedures, the indications ranged from excision of facial swellings to coverage of exposed bone of the hand. The anatomic areas ranged from forehead to the leg. The operating time was relatively greater than in a conventional procedure. However, with experience, the operating time could be halved. The results, without visible external scars, were unparalleled. Endoscopic procedures in anatomic locations where the base was firm, as in the forehead region, were much easier to perform. However, there remains a place for open approach in conditions where the lack of favorable contour or hidden post site does not permit an endoscopic approach; also, when an endoscopic approach takes up an inordinate amount of time for part of a larger procedure. In the five cases of endoscopic muscle harvest, the postoperative pain was significantly less, and the small resultant scars made the procedures worthwhile. Harvest of the upper rectus abdominis muscle for use as an interpolation flap, part of a novel technique, provided excellent vascular flap 
coverage of exposed bone and facilitated early healing, without weakening of the abdominal wall as both anterior and posterior sheaths were left behind. Tailored harvest of fascia lata was done, reducing the risk of muscle herniation of the thigh. Release of restricting bands in congenital torticollis through the axillary approach led the way to the transaxillary approach to the neck for thyroidectomy, which was later adopted in robotic surgery.

The widespread use of endoscopy for subsurface procedures has been restricted by the lack of development of devices or retractors to retain the spaces created by dissection in three dimensions. This paper has simplified the existing approaches in subsurface endoscopy, which are drawn upon a laparoscopic approach. The author uses a single port for most cases and two ports for muscle harvest as a lone operating surgeon with an untrained assistant, as would be the situation for most practitioners in the Indian subcontinent.

\section{Conclusions}

The development of flexible, expansible, self-retaining tunnel retractors and minirobotics are likely to usher the next stage of the endoscopic revolution.

\section{Presented At}

- Annual Meeting of the Association of Plastic, Reconstructive \& Aesthetic Surgeons of Telangana and Andhra Pradesh (APRAS), September 2019, as an invited video presentation (part of this body of work).

- As a video presentation for the CR Sunder Rajan Workshop of the Annual Conferences of Association of Plastic Surgeons of India at Mahabalipuram, August 2011, and at Chandigarh, October 2014 (part of this body of work).

\section{Conflict of Interest}

Nothing to disclose.

\section{Acknowledgments}

I thank Dr. Snehjeet Wagh for his invaluable contribution to the article.

\section{References}

1 Hallock GG. A brief history of minimally invasive plastic surgery. Semin Plast Surg 2008;22(1):5-7

2 Chow JC. Endoscopic release of the carpal ligament: a new technique for carpal tunnel syndrome. Arthroscopy 1989;5(1):19-24

3 Core GB, Vasconez LO, Graham HD II. Endoscopic browlift. Clin Plast Surg 1995;22(4):619-631

4 Ho LC. Endoscopic assisted transaxillary augmentation mammaplasty. Br J Plast Surg 1993;46(4):332-336

5 Johnson GW, Christ JE. The endoscopic breast augmentation: the transumbilical insertion of saline-filled breast implants. Plast Reconstr Surg 1993;92(5):801-808

6 Ramirez OM. Endoscopic full facelift. Aesthetic Plast Surg 1994;18(4):363-371

7 Iglesias M, Bravo L, Chavez-Muñoz C, Barajas-Olivas A. Endoscopic abdominoplasty: an alternative approach. Ann Plast Surg 2006;57(5):489-494

8 Huang MH, Cohen SR, Burstein FD, Simms CA. Endoscopic pediatric plastic surgery. Ann Plast Surg 1997;38(1):1-8

9 Hallock GG. An endoscopic technique for decompressive fasciotomy. Ann Plast Surg 1999;43(6):668-670

10 Hallock GG. Tendon-graft harvest using endoscopic guidance. Plast Reconstr Surg 1996;97(5):1057-1061

11 Hallock GG, Rice DC. An endoscopic subcutaneous dissector for obtaining vein grafts. Ann Plast Surg 1998;41(6):595-599

12 Hallock GG. Endoscopic retrieval of the sural nerve. J Reconstr Microsurg 1995;11(5):347-350

13 Swain B. Transaxillary endoscopic release of restricting bands in congenital muscular torticollis-a novel technique. J Plast Reconstr Aesthet Surg 2007;60(1):95-98

14 Dutta S, Slater B, Butler M, Albanese CT. "Stealth surgery": transaxillary subcutaneous endoscopic excision of benign neck lesions. J Pediatr Surg 2008;43(11):2070-2074

15 Lee CH, Lee C, Trabulsy PP. Endoscopic-assisted repair of a malar fracture. Ann Plast Surg 1996;37(2):178-183

16 Serra JM, Benito JR, Monner J, Zayuelas J, Párraga A. Tissue expansion with endoscopy. Ann Plast Surg 1997;38(2):101-108

17 Hallock GG. Adipofascial flap harvest using endoscopic assistance. Ann Plast Surg 1997;38(6):649-652

18 Hallock GG. Minimally invasive harvest of the gracilis muscle. Plast Reconstr Surg 1999;104(3):801-805

19 Miller MJ, Robb GL. Endoscopic technique for free flap harvesting. Clin Plast Surg 1995;22(4):755-773

20 Saltz R. Endoscopic harvest of the omental and jejunal free flaps. Clin Plast Surg 1995;22(4):747-754

21 Eaves, III, F. Subcutaneous endoscopic plastic surgery using a retractor-mounted endoscopic system. Perspect Plast Surg $1993 ; 7: 1-22$ 